\title{
Silica-Coating and Hydrophobation of CTAB-Stabilized Gold Nanorods
}

\author{
Isabel Pastoriza-Santos, * Jorge Pérez-Juste, * Luis M. Liz-Marzán \\ Departamento de Química Física, Universidade de Vigo, 36310, Vigo, Spain \\ * e-mail: pastoriza@uvigo.es \\ e-mail: juste@uvigo.es
}

\section{Supporting Information}

\section{Experimental Details}

Materials. Tetrachloroauric acid $\left(\mathrm{HAuCl}_{4} \times 3 \mathrm{H}_{2} \mathrm{O}\right)$, silver nitrate $\left(\mathrm{AgNO}_{3}\right)$, sodium borohydride $\left(\mathrm{NaBH}_{4}\right)$, sodium chloride $(\mathrm{NaCl})$, ascorbic acid, conc. $\mathrm{HCl}, \mathrm{NH}_{4} \mathrm{OH}$ (32\%), cetyltrimethyl ammonium bromide (CTAB), tetraethylorthosilicate (TEOS) and octadecyltrimethoxysilane (OTMS) were purchased from Aldrich. Poly(vinylpyrrolidone) (PVP, Mw 10,000) was supplied by Fluka. Poly(styrene sulphonate) (PSS, Mw 14,900) and poly(allylamine hydrochloride) (PAH, Mw 15,000) were procured from Polysciences and Aldrich, respectively. All chemicals were used as received. Pure grade isopropanol, pure grade clhoroform and Milli-Q grade water were used in all preparations.

\section{Characterization}

Transmission electron microscopy (TEM) was carried out with a JEOL JEM 1010 transmission electron microscope operating at an acceleration voltage of $100 \mathrm{kV}$.

UV-Vis-NIR spectra were measured with a Cary 5000 UV-Vis-NIR spectrophotometer. 
Zeta potential was determined through electrophoretic mobility measurements, using a Malver Zetasizer 2000 instrument.

Nanorod synthesis. First, a gold seed solution was prepared by borohydride reduction of $5 \mathrm{~mL} 0.25 \mathrm{mM} \mathrm{HAuCl}_{4}$ in an aqueous CTAB solution $0.1 \mathrm{M}$. The average particle size measured from TEM was $2.83 \pm 0.68 \mathrm{~nm}$. For the synthesis of the gold nanorods $24 \mu \mathrm{L}$ of seed solution was added to a growth solution containing $0.1 \mathrm{M}$ CTAB, $0.5 \mathrm{mM}$ $\mathrm{HAuCl}_{4}, 0.6 \mathrm{mM}$ ascorbic acid and $0.12 \mathrm{mM}$ silver nitrate. The gold nanorod dimensions obtained from TEM were $12.9 \pm 1.9 \times 52.1 \pm 8.2 \mathrm{~nm}$, with an aspect ratio of $4.1 \pm 0.8$.

Polyelectrolyte Coating. Typically, $10 \mathrm{~mL}$ of as prepared gold nanorods were centrifuged at $8000 \mathrm{rpm}$ during 20 minutes, the supernatant was discarded and the precipitate redispersed in $5 \mathrm{~mL}$ of Milli-Q water. Subsequently, it was added dropwise to $5 \mathrm{~mL}$ of PSS $(2 \mathrm{~g} / \mathrm{L}, 6 \mathrm{mM} \mathrm{NaCl})$ aqueous solution (previously sonicated during 30 minutes) under vigorous stirring. Stirring was continued for $3 \mathrm{~h}$, centrifuged twice at $4500 \mathrm{rpm}$, to remove excess polyelectrolyte, and redispersed in $5 \mathrm{~mL}$ of Milli-Q water. Thereafter, it was added dropwise to $5 \mathrm{~mL}$ of $\mathrm{PAH}(2 \mathrm{~g} / \mathrm{L}, 6 \mathrm{mM} \mathrm{NaCl})$ aqueous solution (previously sonicated during 30 minutes) under vigorous stirring. Stirring was continued for 3 hours, centrifuged once at 4500 rpm, to eliminate excess PAH, and redispersed in $5 \mathrm{~mL}$ of Milli-Q water.

PVP coating. $5 \mathrm{~mL}$ of PSS/PAH coated gold nanorods were mixed with $5 \mathrm{~mL}$ of PVP (Mw 10 000, 4g/L) aqueous solution and stirred overnight. The mixture was centrifuged at $4500 \mathrm{rpm}$, the clear supernatant discarded and the precipitate redispersed in $0.2 \mathrm{~mL}$ of water. The aqueous dispersion of PVP coated gold nanorods was added to $1 \mathrm{~mL}$ of isopropanol dropwise and under vigorous stirring. The concentration in terms of gold in this stage is around $2.47 \mathrm{mM}$.

Zeta potential values of $+20 \mathrm{mV},-30 \mathrm{mV},+36 \mathrm{mV}$ and $+16 \mathrm{mV}$ were measured for the AuNR@CTAB,AuNR@PSS, AuNR@PSS@PAH and AuNR@PSS@PAH@PVP, respectively.

Silica coating. The PVP coated gold nanorod dispersion $(1.2 \mathrm{~mL})$ was added under vigorous stirring to $0.46 \mathrm{~mL}$ of water, then $1.43 \mathrm{~mL}$ of ammonia solution in isopropanol 
(3.84 vol.\% ammonia (33 $\mathrm{wt} \%$ in water) in isopropanol) was added under vigorous stirring and finally $0.40 \mathrm{~mL}$ of a solution of TEOS in isopropanol (0.97 vol\% of TEOS) was added under gentle stirring. The reaction mixture was allowed to react for $2 \mathrm{~h}$. At this point the gold nanorods present a $12 \mathrm{~nm}$ thick silica shell. Further additions of TEOS were carried out to grow the silica shells.

Solvent transfer. Surface modification was carried out following the procedure published by Wang et al. for hydrophobation of silica surfaces using the silane coupling agent octadecyltrimethoxysilane. Briefly, to $3 \mathrm{~mL}$ of $\mathrm{Au}$ rod@ $\mathrm{SiO}_{2} 0.78 \mathrm{mM}$ (in ethanol) containing $30 \mu \mathrm{L}$ of $\mathrm{NH}_{4} \mathrm{OH}$ (32\%) was added dropwise with vigorous stirring $300 \mu \mathrm{L}$ of OTMS chloroform solution (2.4\%). Grafting was achieved by hydrolysis of methoxy groups and condensation of the resulting silane triols with surface Si-OH groups. After 24 h, the particles were separated by centrifugation, washed with ethanol and then dispersed in chloroform. 


\section{Supporting information Figures}

\section{Silica coated gold nanorods trough the use of PVP as capping agent}

The application of Stöber method to PVP-coated Au nanorods does not lead to silica coated nanoparticles but the nucleation of free silica particles.
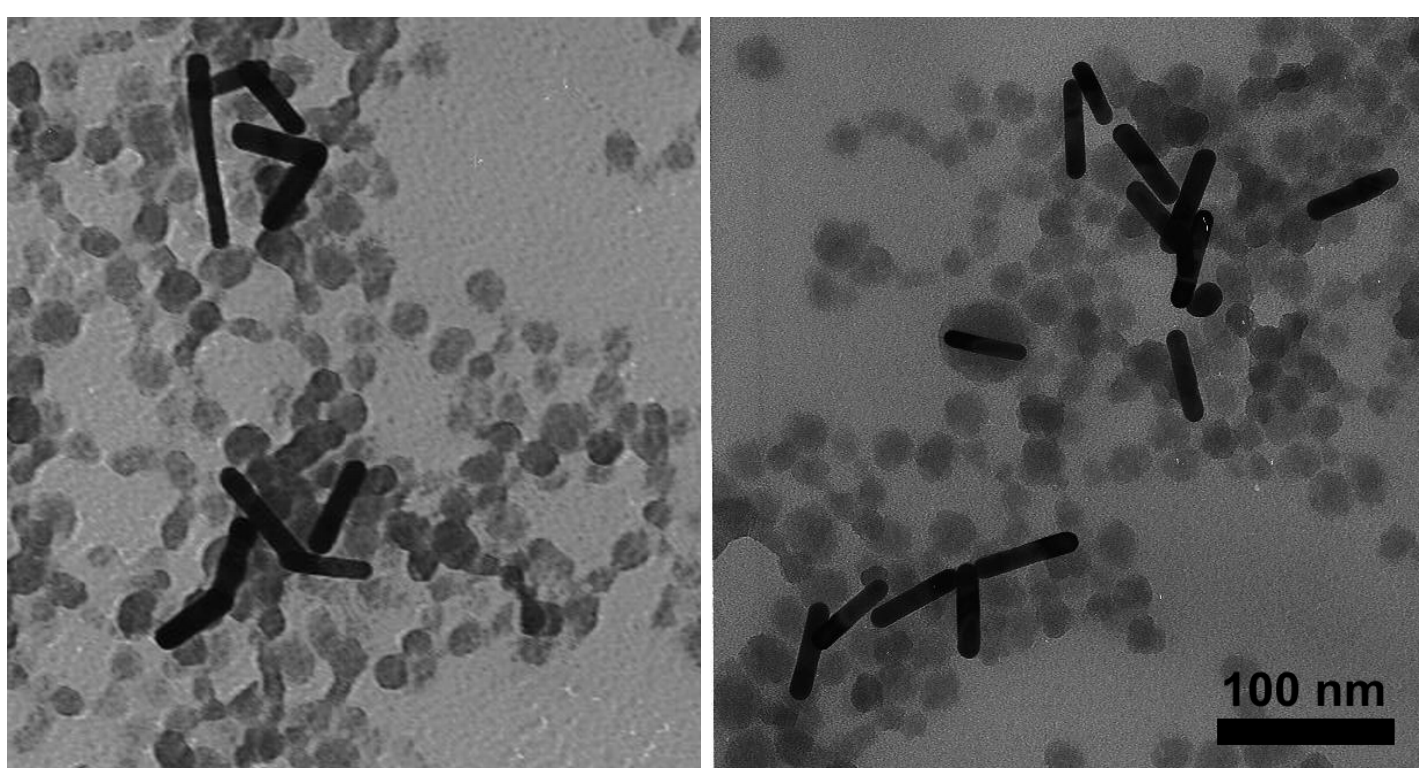

Figure S1. Images of non coated Au nanorod nanoparticles and free silica particles. 


\section{Silica coating of CTAB stabilized gold nanoparticles.}

The silica coating protocol has been successfully applied to other CTAB stabilized gold nanoparticles with different sizes and shapes. An example is shown in Figure S2.

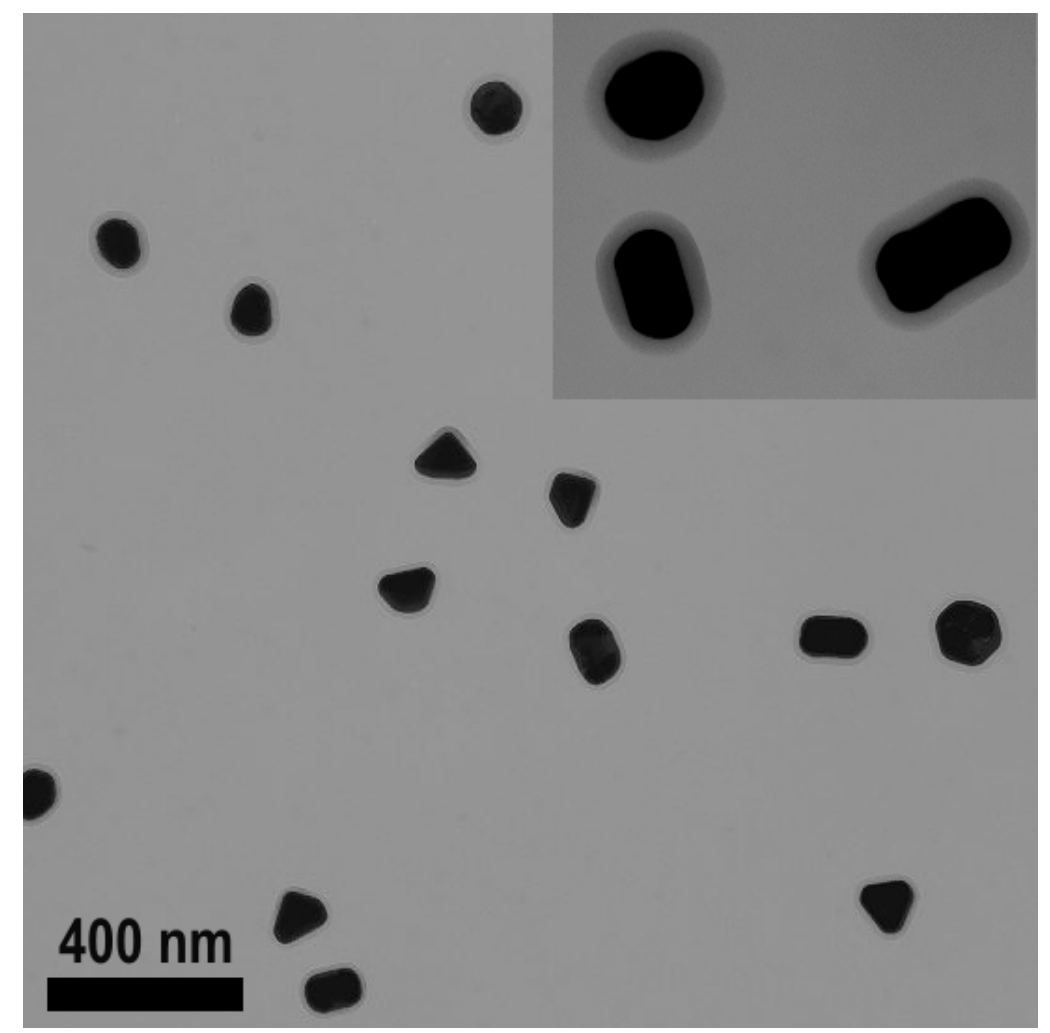

Figure S2. TEM image of CTAB stabilized gold nanoparticles uniformly coated with silica. 
OTMS modified, hydrophobic Au@SiO 2 nanorods
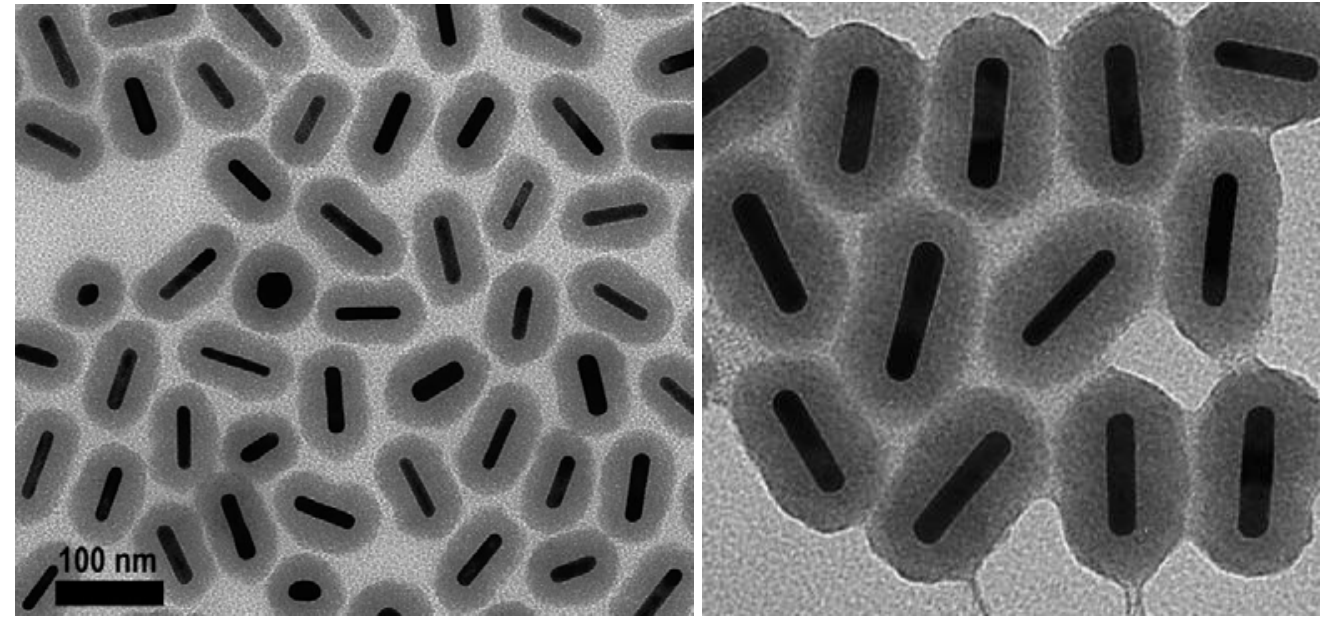

Figure S3. TEM images of OTMS modified Au@SiO ${ }_{2}$ nanorods. 